\title{
Individual and community level associates of contraceptive use in Ethiopia: a multilevel mixed effects analysis
}

\author{
Masrie Getnet Abate ${ }^{1}$ and Amare Abera Tareke ${ }^{2^{*}}$ (D)
}

\begin{abstract}
Background: Family planning is one of the four pillars of safe motherhood initiative to reduce maternal death in developing countries. Despite progress in contraceptive use, unmet needs are wide open and fertility remains high. Ethiopia have a higher fertility rate which contributes to maternal and child health destitution, putting pressure on the already weak health system. This study examined individual and community-level factors associated with contraceptive use in Ethiopia.

Methods: Data from Ethiopian Demographic and Health Survey 2016 were used to identify individual and community level associated factors among reproductive-age women. Non-pregnant, fecund and sexually active women aged 15-49 were included. Six hundred forty-two communities and 6854 women were involved from this two-stage cluster sampled data. The analysis was done using two-level mixed-effects logistic regression to determine fixed effects of individual and community-level factors and random intercept of between characteristics.

Results: From the total eligible women for contraceptive use 2393 (34.9\%) of them were users. Injectables were the commonest of all contraceptive methods. Various individual-level variables were associated with contraceptive use. Household wealth index, women's age, number of living children, husband's occupation, ever experience of a terminated pregnancy, current working status of the women, number of births in the last 3 years, and hearing of FP messages through different media were significantly associated individual-level variables after adjusting other factors. Community characteristics like region, place of residence, religion, and community-level wealth were the factors associated with contraceptive use.

Conclusion: Both individual and community-level characteristics were significant predictors of use of contraceptives in Ethiopian women. Besides the individual-level factors, interventions should also consider community-level associates.
\end{abstract}

Keywords: Contraceptive use, Ethiopia, Individual and community-level characteristics, Multilevel analysis

\section{Background}

In the current growth rate of the world population, $1.13 \%$, about 80 million people will be added per year [1]. The United Nations estimates the World population will increase from 7.4 billion in 2016 to 8.1 billion in 2025 , with the most growth in developing countries and more than half in Africa [2]. With the highest rate of population growth, Africa is expected to account for

\footnotetext{
*Correspondence: amareabera8@gmail.com

${ }^{2}$ Department of Biomedical Sciences, Institute of Health, Jimma University, Jimma, Ethiopia

Full list of author information is available at the end of the article
}

more than half of the world population growth between 2015 and 2050 [2]. Ethiopia, a second populous nation in Africa, had an average of 4.6 children per women in 2016 [3]. This figure puts Ethiopia among countries with higher fertility rates in the world. Fertility rates are determinant factors in human development index (HDI) affecting life expectancy, education, per capita and other indicators [4]. The role of modern contraceptives in decreasing maternal and child mortality, and other health costs thereby improving maternal and child health is widely advocated $[5,6]$.

(C) The Author(s). 2019 Open Access This article is distributed under the terms of the Creative Commons Attribution 4.0 International License (http://creativecommons.org/licenses/by/4.0/), which permits unrestricted use, distribution, and 
The use of modern contraceptives ranges from $3.6 \%$ in the Somali region to $56.3 \%$ in Addis Ababa with a national prevalence of $27.3 \%$ in 2011 [7]. The use of modern contraceptives has variation with different factors, creating difficulty to determine the national figure and its determinants. Although there are recent improvements, developing countries including Ethiopia, carry the most significant proportion of maternal and child mortality with multi-factorial etiology $[8,9]$. The major obstacle for improvements in maternal and child health services is continued population growth with sustained high fertility rate, placing considerable strain on the already fragile health system [9]. Contraceptive methods are currently recommended to decrease higher total fertility rates especially in developing countries like Ethiopia [10].

Modern contraceptives in Ethiopia are available in every health facility free of cost and pushing to increase utilization. The use of contraceptives in Ethiopia usually focused on short-acting methods like birth control pills and injectable, which have a high chance of discontinuation $[11,12]$. Fears of side effects, health concerns, low knowledge of women, lower educational level, men's (partner's) objection, male partner desire for more children, and lack of women's decision making power are barriers for contraceptive utilization especially in longacting and permanent methods [13].

The number of children, women's current age, age at first marriage, education, religious affiliation, media exposure about family planning, wealth index, occupation, husband's occupation, place of residence, husbands approval couple's discussion, are the main determinant factors for utilization of modern contraceptives among married women of reproductive age [11, 12, 14, 15].

Several community-level factors were found to be associated with contraceptive use elsewhere. Access to family panning in nearby store or health facility, female autonomy, female education, religion, place of residence, proportions of polygynous marriages and community level media exposure were community-level determinants in Nigeria [16, 17]. Average community wealth and the women's relative socioeconomic position within the community have significant positive effects on the use of modern contraceptives in Mozambique. And also, the contextual effects due to community wealth were greater in rural than in urban areas [18]. A study in Poland found that the contraceptive behavior of friends and family is more influential than are women's own characteristics and that community-level characteristics additionally influence contraceptive use [19].

Representative studies on the use and determinants of modern contraceptives in Ethiopia are scares. Besides deficiency of fertile evidence, small inconclusive studies in different areas without considering community-level factors put different dissimilar, mutually exclusive determinant factors, lacking to draw relevant conclusions in national level.

Generally, even if previous studies have given important clues to policymakers, programmers, and other stakeholders, they mainly lack consistency and representatives to be used for national-level policy making and programming by concerned bodies. Thus, the present study aims to determine multilevel determinants of modern contraceptive use among married women of the reproductive age group in Ethiopia using the 2016 Ethiopian Demographic Health Survey (EDHS 2016) data.

\section{Methods}

\section{Study design and setting}

Ethiopia is the second populous country in Africa next to Nigeria with a population of more than one hundred million. Administratively, Ethiopia is divided into nine geographical regions (Tigray, Afar, Amhara, Oromia, Somali, Benishangul-Gumuz, SNNPR, Gambella and Harari) and two administrative cities, Addis Ababa and Diredawa. Ethiopia shares the boundaries in the North with Eritrea, in the South with Kenya and Somalia, in the West with South Sudan and North Sudan, in the East with Djibouti and Somalia. The survey was a population-based crosssectional study conducted from January 18, 2016, to June 27,2016 , across the country [20].

\section{Data source}

The dataset used in this study was obtained from MEASURE DHS database at http://dhsprogram.com/ data/ after getting the approval letter from DHS program office for 2016 Ethiopian Demographic and Health Survey, which is the fourth comprehensive survey.

\section{Sampling procedures}

The 2016 EDHS sample was stratified and selected in two stages. In the first stage, a total of 645 clusters (202 in urban areas and 443 in rural areas) were selected based on 2007 population housing census. A household listing was carried out in all of the selected clusters from September to December 2015, served as a sampling frame for the selection of households in the second stage.

A representative sample of 18,008 households was selected for the 2016 EDHS. From the interviewed households, 16,583 eligible women were identified for individual interviews. Interviews were completed with 15,683 women, yielding a response rate of $95 \%$ [16]. In this study, a total of 6854 eligible women from 642 clusters (201 in urban and 441 in rural) were included after the necessary exclusion criteria were carried out, summarized as Fig. 1. 


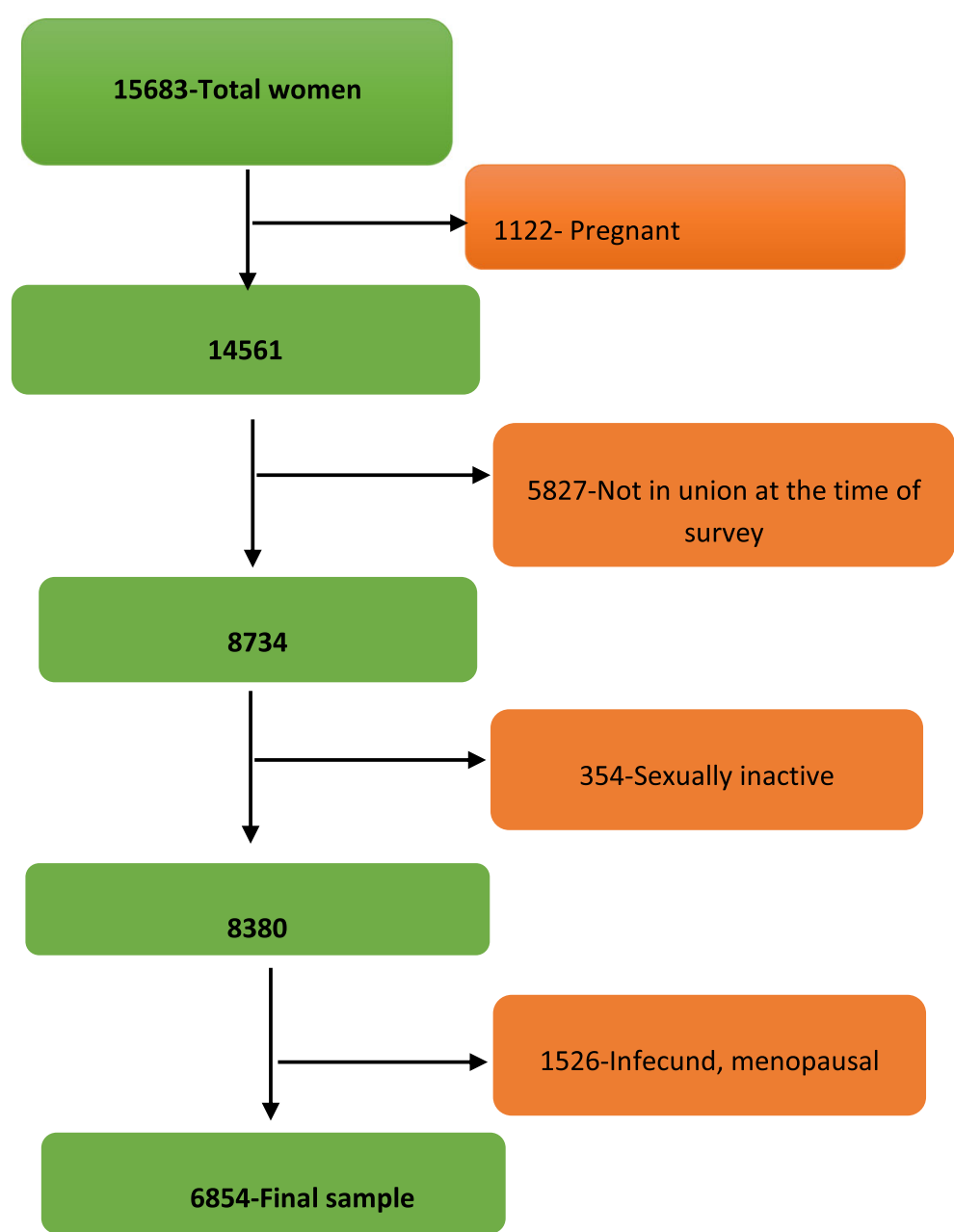

Fig. 1 Schematic illustration of women included in the study. From women's health survey 15,683 women participated in the survey. Several exclusion criteria were used to reach the final sample for this study. Pregnant women were 1122 during the survey period and were excluded in the first step. The other criteria used for eligibility to this study was women should be married or were in union with their couple during the survey. A significant number of women excluded by failing to fulfill this criterion. After screening for sexual activity and fecundity we reached the final sample size of 6854

\section{Study variables}

\section{Dependent variable}

The dependent variable is current contraceptive use among married women in reproductive age. Current use of contraceptives was dichotomized, women were categorized as "users" to indicate the use of any modern contraceptive methods and "non-users" to represent those who were not using any contraceptive method or using Folkloric and Traditional methods.

\section{Independent variables}

The independent variables for contraceptive utilization were based on the previous literature and availability of the variable on 2016 EDHS dataset. Variables were broadly classified into two main groups, individual level and community level variables aligned for multilevel analytic approach.

\section{Individual-level variables}

Age of women at the time of survey, educational level of women, household wealth index, total number of living children, husband's occupation, exposure to mass media, experience of terminated pregnancy, history of smoking cigarettes, current working status of women, births in the last 3 years, hearing of family planning messages through media, Visit of health facility in the last 12 months and husband's desire for children were included as individual-level variables.

\section{Community-level variables}

Region and place of residence were regarded as community-level variables directly from EDHS but the remaining variables are not available directly from EDHS. Hence, we aggregated the variables at the community-level based on the individual information 
and then the aggregated values were classified as low and high if the median values or the proportions of the clusters were below and above the national level respectively. Having this, community-level religious affiliation, community-level media exposure about family planning, community level women employment, community-level of health facility visit and community-level wealth were considered as community-level variables.

\section{Region}

The EDHS was collected from administratively divided of nine regions and two federal's administrative cities. We used these administrative boundaries as communitylevel factor.

\section{Place of residence}

It was classified as rural and urban, considered as a community level factor.

\section{Community-level religion}

From the distribution of Muslims in the cluster, the proportion of Muslims was taken and a cut of value of $42.7 \%$ was considered. Clusters having greater than $42.7 \%$ of women Muslims regarded as high community level Muslim prevalence and less than $42.7 \%$ of women Muslims in the cluster was considered as low community level Muslim prevalence.

\section{Community-level media exposure}

Information heard about family planning from radio, $\mathrm{TV}$, and magazine/newspaper were considered together. If a woman had exposure for at least one of the three, we consider as she had media exposure. If greater than or equal to $50 \%$ of the cluster members heard information, we considered as having high community-level information. If less than $50 \%$ of the cluster members had no information, the cluster was classified as having low information from media.

\section{Community-level employment}

Classified based on national women employment proportion. Thirty-three percent of women nationally were working during the survey. Clusters were classified high community-level employment if greater than or equal to $33 \%$ of the members were currently working, or low if less than $33 \%$ of cluster members were not working.

\section{Community-level visit of health facility}

Classified as high and low by taking $51 \%$ cluster members as the reference according to the national data.

\section{Community-level wealth}

Classified based on the wealth index of the household. The median value of the wealth index at the national level was 3 . Then the aggregated clusters were classified into low if the median value of the cluster was below 3 and high if the median value of the cluster was greater than or equal to 3.

\section{Data analysis}

In this study, two-level mixed-effects logistic regression analyses were employed using $\mathrm{R}$ software (version 3.5.3). Since the EDHS data was hierarchical, i.e., women were nested in household and household were nested in cluster multi-level analysis is recommended. First, bivariate twolevel mixed-effect logistic regression analyses were done to assess the association between the independent variables and the dependent variable of the study. The overall categorical variables with a $p$-value of $<0.25$ at the bivariate two-level mixed-effect logistic regression analysis were included into the final model of multivariable two-level mixed effect logistic regression model in which odds ratio with $95 \%$ confidence intervals were estimated to identify independent variables of modern contraceptive use. $P$ values less than 0.05 were employed to declare statistical significance. Fixed effect and random effect were calculated to assess the individual and cluster variations respectively. Moreover, the descriptive statistics were displayed for the community and individual variables.

Thus, four models are displayed in this analysis, Null model (model containing no factors), Model I (containing only individual factors), Model II (containing only community factors) and Model III (both individual and community-level factors). The fitted model was:

$$
\log \left[\frac{\pi_{i j}}{1-\pi_{i j}}\right]=\beta_{0}+\beta_{1} \mathrm{X}_{1 i j}+\ldots \beta_{n} \mathrm{X}_{n i j}+u o_{j}+e_{i j},
$$

Where

$\checkmark \pi_{i j}$-the probability of women who currently using contraceptive

$\checkmark 1-\pi_{i j}$ - the probability of not using modern contraception

$\checkmark \beta_{0}$ is log odds of the intercept

$\checkmark \beta_{1} \ldots \beta_{n}$ - the amount of effect by the individual and community-level variables

$\checkmark \mathrm{X}_{1} \ldots \mathrm{X}_{n}$ - the independent variables at individual and community level

$\checkmark u o_{j}$ - the random error at community(cluster) and

$\checkmark e_{i j}$ - the random error at the individual level.

The intra-class correlation (ICC) was calculated as the proportion of the between cluster variation in the total variation:

$$
I C C=\frac{\operatorname{Var}\left(u_{o j}\right)}{\operatorname{Var}\left(u o_{j}\right)+\pi^{2} /{ }_{3}},
$$

Where, 
$\checkmark \operatorname{Var}\left(u_{o j}\right)$ is the community (cluster) level variance. $\checkmark \pi^{2} / 3$ is the standard logistic distribution, that is, the assumed household variance component, which is $\pi^{2} / 3 \approx 3.29$.

The variability on the odds of modern contraceptive users explained by successive models were calculated by Proportional Change in Variance (PCV) as:

$$
P C V=\frac{V_{e}-V_{m i}}{V e},
$$

Where,

$\checkmark V_{e}$ - the variance in modern contraceptive utilizations in the null model.

$\checkmark V_{m i}$ - the variances in the successive models.

\section{Results}

\section{Prevalence of contraceptive use}

From 2016 EDHS data set a total of 6854 married, nonpregnant and fecund women were included for this study. Of these fecund women, 2393 (34.9\%) of them were users of contraceptive methods. Injectables were the most commonly used contraceptive methods (59.1\%), the percentage of users in each contraceptive type is summarized in Fig. 2.

More than half of the women had no formal education [3891(56.8\%)], and only $14.2 \%$ of them had attended secondary education or higher. By contrast, their husband had a better education with a decreased number of no formal education males 2981(43.5\%), again 28.3\% of them had secondary education or higher. More than two-thirds of women 4696 (68.5\%) had either one or two under-five children, while less the one-fourth of the total 1446(21.1) had no under-five children. Majority of the women 4674(68.2\%) were not working in the time of the survey, this figure is bigger when we consider the husband's status of 681(9.9\%), indicating disparities in work. Summarized in Table 1: Background characteristics of married non-pregnant women, Ethiopian Demographic and Health Survey $2016(n=6854)$.

Exposure to mass media including radio, television, magazine/newspaper, at least for one of the media, remains below half of the study population. Only $41 \%$ of the women had exposure to medias 12 months preceding the survey. Media exposure for family planning was also low with $2090(30.5 \%)$ of mothers heard through radio or TV or newspaper in the last few months before the survey. Health insurance coverage was extremely low as well. More than $95 \%$ of the women were no insured. While 1 in 10 mothers experienced a terminated pregnancy, smoking in reproductive age fecund Ethiopian women was low (1\%). The mean age of mothers during the survey was 29 years, the median value for under-five children in the household during the survey was one child and the mean value for the number of total living children in the household preceding to the 2016 EDHS were three.

From the total 645 EDHS clusters, 642 clusters had married, non-pregnant reproductive age women eligible for contraceptive use and included in this study. Below onethird of clusters were from urban areas. Three hundred eighty-two (59.5\%) of clusters had lower Muslim proportions at the community level. Comparing with the median

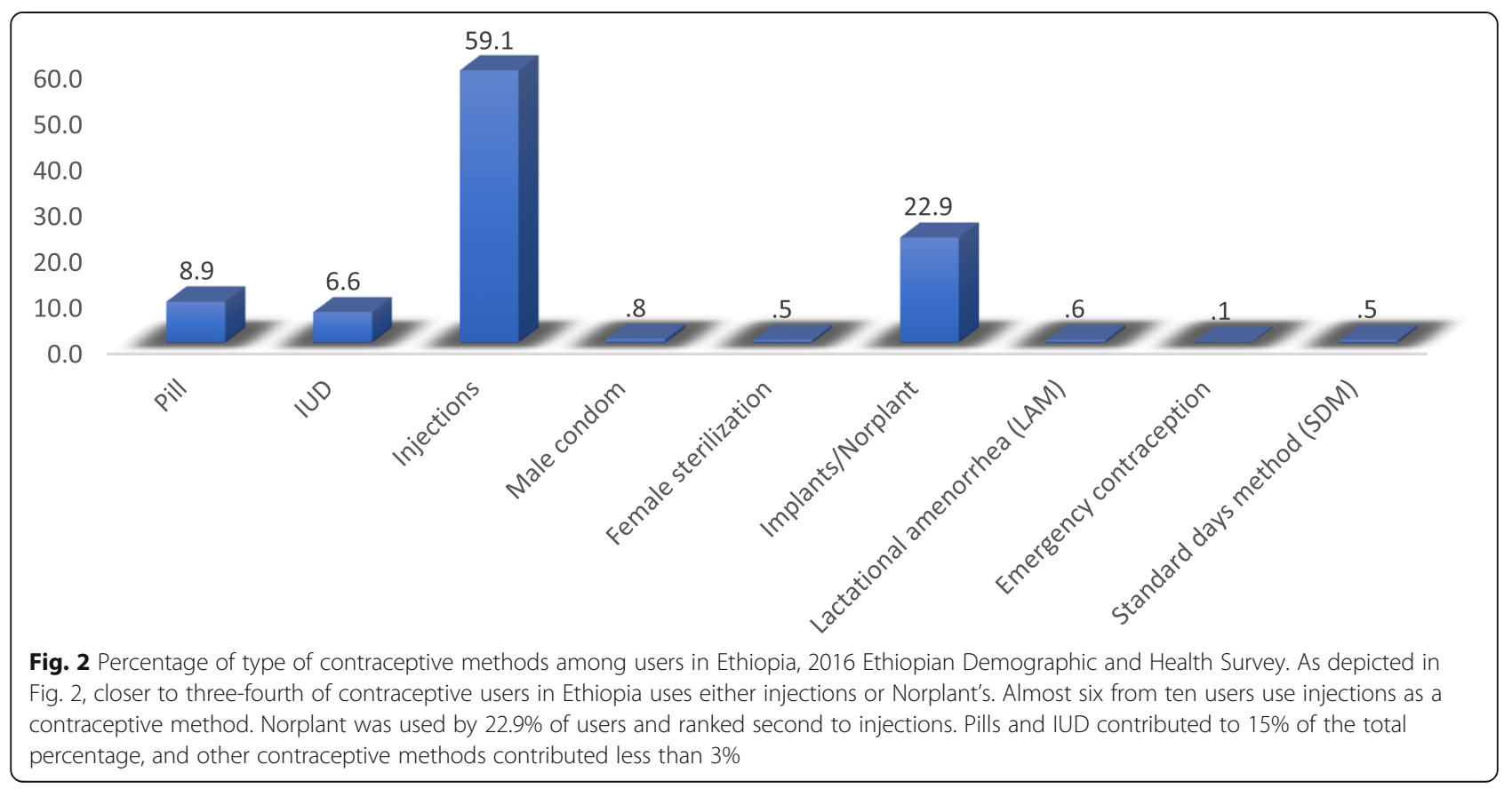


Table 1 Background characteristics of married non-pregnant women, Ethiopian Demographic and Health Survey 2016 $(n=6854)$

\begin{tabular}{llll}
\hline Individual Variables & Categories & Frequency & $\%$ \\
\hline Age in 5-year groups & $15-19$ & 500 & 7.3 \\
& $20-24$ & 1343 & 19.6 \\
& $25-29$ & 1668 & 24 \\
& $30-34$ & 1357 & 19.8 \\
& $35-39$ & 1120 & 16 \\
& $40-44$ & 607 & 8.9 \\
& $45-49$ & 259 & 3.8
\end{tabular}

Highest educational level

No education
Primary
Secondary
Higher

Religion

Christians
Muslin
Other

Number of children

5 and under in household

None
$1-2$
$>=3$

Number of living

children categories

None
$\begin{aligned} & 1-4 \\ & 5-8 \\ & >=9\end{aligned}$

Births in last 3

years category

None
one birth
more than two births

3840

2927

446

4696

712

665

4154

1879

156

more than two births

Wealth index combined

Poor

Middle

Rich

Respondent

currently working

No

Yes

Exposure to mass media

No

Yes

History of terminated pregnancy

\section{No}

Yes

Heard family planning

through media
Table 1 Background characteristics of married non-pregnant women, Ethiopian Demographic and Health Survey 2016 ( $n=6854)$ (Continued)

\begin{tabular}{llll}
\hline Individual Variables & Categories & Frequency & $\%$ \\
\hline $\begin{array}{l}\text { Visited by fieldworker } \\
\text { in last 12 months }\end{array}$ & & & \\
& No & & \\
& Yes & 2017 & 29.4 \\
$\begin{array}{l}\text { Did fieldworker talk } \\
\text { about family planning }\end{array}$ & & & \\
& No & & 36.5 \\
& Yes & 787 & 63.5 \\
$\begin{array}{l}\text { Visited health facility } \\
\text { in the last 12 months }\end{array}$ & & 1230 & \\
& No & & 48.5 \\
& Yes & 3322 & 51.5
\end{tabular}

At health facility, told

of family planning
No

Yes

History of smoking Cigarette

Covered by health insurance

Husband's desire for children

Both want same

Husband wants more

Husband wants fewer

Don't know

6572

95.9

282

4.1

Husband/partner's education level

Primary 2213

Secondary $\quad 868 \quad 127$

$\begin{array}{lll}\text { Higher } & 728 & 10.6\end{array}$

Husband/partner's

occupation (grouped)

Did not work

681

9.9

Clerical/sales/services/skilled labor

Professional/technical/managerial

4601

Person who usually decides on respondent's health care

\section{Respondent alone}

1242

18.1

Respondent and husband/partner

4343

Husband/partner alone

Someone else

Other

Current use of

contraceptive methods

No education $\quad 3045$


educational level of the country, women in 306 (55.8\%) clusters had lower education. Almost half of the clusters had lower employment status, and media exposure about family planning was poor even at community-level. Description of community-level variables was presented in Table 2 Description of cluster background characterstics among reproductive age women in Ethiopia, Ethiopian Demographic and Health Survey $2016(n=642)$.

\section{Multilevel analysis}

A two-level mixed-effect logistic regression was used to analyze the effect of women's individual characteristics and community-level factors in determining women's use of contraceptives. As depicted in the empty model $40 \%$ of the total variance in the odds of contraceptive use was accounted by between cluster variation of characteristics. The between cluster variability declined over successive models from $40 \%$ in the empty model into $23 \%$ in individual-level only model, $16 \%$ in community-level factors only model and $14 \%$ in the combined model. Thus, the combined model of individual-level and community-level factors were preferred for predicting women's contraceptive use.

\section{Individual level determinants}

In the model I only individual-level variables were added. The result signified that wealth index, women's age, number of living children, husband's occupation, ever experience of a terminated pregnancy, current working status of the women, number of births in the last 3 years, and hearing of family planning messages through different media were significantly associated variables with contraceptive use.

The ICC in Model I indicated that $23 \%$ of the variation in contraceptive use was attributable to difference across the communities. From PCV in Tables 3, 82.5\% of the variance in contraceptive use across communities was explained by individual-level factors.

The number of living children affects women's use of contraceptive at the individual level. Women with 1-4 children have higher odds of using contraceptive $\mathrm{OR}=$ $3.6(95 \%$ CI $2.8,4.7)$ than women with no living children. Even the odds were highest in women having living children between five and eight $4.0(95 \%$ CI $2.8-5.5)$, although the odds have slightly decreased for women having more than 8 children there was a significant difference with those no living children at all $3.2(95 \% \mathrm{CI}$ $1.7,6.1)$. Wealth index was another factor influencing women's use of contraceptive, as wealth index increases from poor to rich the odds of using contraceptive was also increased. Compared to the poor the middle and the rich had higher odds 1.4(95\% CI 1.1, 1.7).

Among several husband's characteristics that affect women's use of contraceptive methods, one was partner's
Table 2 Description of cluster background characterstics among reproductive age women in Ethiopia, Ethiopian Demographic and Health Survey $2016(n=642)$

\begin{tabular}{|c|c|c|c|}
\hline Community level variables & Categories & Frequency & $(\%)$ \\
\hline \multicolumn{4}{|l|}{ Region } \\
\hline & Tigray & 722 & 10.5 \\
\hline & Afar & 589 & 8.6 \\
\hline & Amhara & 839 & 12.2 \\
\hline & Oromia & 933 & 13.6 \\
\hline & Somali & 618 & 9.0 \\
\hline & Benishangul & 569 & 8.3 \\
\hline & SNNPR & 817 & 11.9 \\
\hline & Gambela & 439 & 7.1 \\
\hline & Harari & 380 & 5.5 \\
\hline & Dire dawa & 406 & 5.9 \\
\hline & Addis Ababa & 492 & 7.2 \\
\hline \multicolumn{4}{|l|}{ Type of place of residence } \\
\hline & Urban & 201 & 31.3 \\
\hline & Rural & 441 & 68.7 \\
\hline \multicolumn{4}{|c|}{ Muslim Religion at the community level } \\
\hline & low & 382 & 59.5 \\
\hline & high & 260 & 40.5 \\
\hline \multicolumn{4}{|l|}{ Wealth } \\
\hline & Low & 269 & 41.9 \\
\hline & High & 373 & 58.1 \\
\hline \multicolumn{4}{|c|}{$\begin{array}{l}\text { Employment status of women } \\
\text { at the community level }\end{array}$} \\
\hline & low & 317 & 49.4 \\
\hline & high & 325 & 50.6 \\
\hline \multicolumn{4}{|l|}{$\begin{array}{l}\text { Heard family planning on } \\
\text { media at community level }\end{array}$} \\
\hline & low & 363 & 56.5 \\
\hline & high & 279 & 43.5 \\
\hline \multicolumn{4}{|c|}{ Media exposure at community level } \\
\hline & low & 253 & 39.4 \\
\hline & high & 389 & 60.6 \\
\hline \multicolumn{4}{|c|}{ Husbands desire for more children } \\
\hline & Low & 283 & 44.1 \\
\hline & High & 359 & 55.9 \\
\hline \multicolumn{4}{|l|}{ Terminated pregnancy } \\
\hline & low & 369 & 57.5 \\
\hline & high & 273 & 42.5 \\
\hline \multicolumn{4}{|l|}{ Visit health institution } \\
\hline & Low & 257 & 40.0 \\
\hline & High & 385 & 60.0 \\
\hline \multicolumn{4}{|l|}{$\begin{array}{l}\text { Visited by field worker at } \\
\text { the community level }\end{array}$} \\
\hline & low & 361 & 56.2 \\
\hline & high & 281 & 43.8 \\
\hline \multicolumn{4}{|l|}{ Coverd by health insurance } \\
\hline & Low & 525 & 81.8 \\
\hline & High & 117 & 18.2 \\
\hline
\end{tabular}


Table 3 Multilevel regression results assessing effects of individual and community level characteristics on contraceptive use among women in Ethiopia, 2016 Ethiopian Demographic and Health Survey

\begin{tabular}{lllll}
\hline $\begin{array}{l}\text { Variables/ } \\
\text { characteristics }\end{array}$ & $\begin{array}{l}\text { Null } \\
\text { model }\end{array}$ & $\begin{array}{l}\text { Model I } \\
\text { Individual } \\
\text { characteristics }\end{array}$ & $\begin{array}{l}\text { Model II } \\
\text { Community } \\
\text { level } \\
\text { characteristics }\end{array}$ & $\begin{array}{l}\text { Model III } \\
\text { Individual and } \\
\text { community-level } \\
\text { characteristics }\end{array}$ \\
& OR (95\%Cl) & OR $(95 \%$ Cl) & OR $(95 \%$ Cl) \\
\hline
\end{tabular}

\begin{tabular}{lll}
\hline Educational level of women & & \\
$\begin{array}{l}\text { No formal } \\
\text { education (Ref) }\end{array}$ & & \\
Primary & $1.3(1.1,1.5) * *$ & $1.2(1.0,1.4)$ \\
Secondary & $1.4(1.1,1.8)^{* *}$ & $1.2(0.9,1.5)$ \\
Higher & $1.5(1.1,2.0) * *$ & $1.2(0.8,1.6)$
\end{tabular}

Wealth index

$\begin{array}{ll}\text { Poor }{ }^{\text {(ref }} & \\ \text { Middle } & 1.9(1.5,2.3) * * * \\ \text { Rich } & 2.2(1.8,2.6)^{* * *} \\ \text { Age } & \\ 35-39^{\text {(ref) }} & \\ 15-19 & 1.6(1.1,2.2)^{* *} \\ 20-24 & 2.1(1.6,2.7) * * \\ 25-29 & 1.7(1.3,2.1)^{* * *} \\ 30-34 & 1.3\left((1.0,1.6)^{*}\right. \\ 40-44 & 1.0(0.8,1.4) \\ 45-49 & 0.6(0.4,0.9)^{*}\end{array}$

Number of living children

$\begin{array}{ll}\text { None }^{(\text {reff }} & \\ 1-4 & 3.6(2.7,4.7)^{* * *} \\ 5-8 & 3.5(2.5,4.9)^{* * *} \\ >=9 & 2.5(1.3,4.8)^{* *}\end{array}$

Husband/partner's occupation

Did not work ${ }^{\text {(reen }}$

Farming/unskilled

Clerical/sales/

services/skilled

labor

professional/

technical/manager

Others

$2.0(1.5,2.6) * * *$
$2.1(1.6,2.8)^{* * *}$
$1.9(1.4,2.7)^{* * *}$
$1.5(1.0,2.2)^{*}$

Exposure to mass media

$$
\begin{aligned}
& \mathrm{No}^{\text {(ref) }} \\
& \text { Yes }
\end{aligned}
$$$$
1.2(1.0,2.2) *
$$

Ever had a terminated pregnancy

$$
\begin{aligned}
& \mathrm{No}^{\text {(ref) }} \\
& \text { Yes }
\end{aligned}
$$$$
0.7(0.6,0.9) *
$$

Smokes cigarettes

$$
\mathrm{No}^{\text {(ref) }}
$$$$
\text { Yes }
$$$$
0.8(0.4,1.5)
$$

Respondent currently working status

$$
\mathrm{No}^{\text {(ref) }}
$$$$
\text { Yes }
$$

Births in the last 3 years

$1.1(1.0,1.4)$

\begin{tabular}{|c|c|c|c|c|}
\hline \multirow{3}{*}{$\begin{array}{l}\text { Variables/ } \\
\text { characteristics }\end{array}$} & \multirow{3}{*}{$\begin{array}{l}\text { Null } \\
\text { model }\end{array}$} & Model I & Model II & Model III \\
\hline & & $\begin{array}{l}\text { Individual } \\
\text { characteristics }\end{array}$ & $\begin{array}{l}\text { Community } \\
\text { level } \\
\text { characteristics }\end{array}$ & $\begin{array}{l}\text { Individual and } \\
\text { community-level } \\
\text { characteristics }\end{array}$ \\
\hline & & OR $(95 \% \mathrm{Cl})$ & OR $(95 \% \mathrm{Cl})$ & OR (95\%Cl) \\
\hline \multicolumn{5}{|l|}{ No birth ${ }^{\text {(ref) }}$} \\
\hline One birth & \multicolumn{3}{|c|}{$0.5(0.4,0.6) * * *$} & $0.5(0.4,0.6)^{* * *}$ \\
\hline $\begin{array}{l}\text { Two and more } \\
\text { births }\end{array}$ & \multicolumn{3}{|c|}{$0.2(0.1,0.3) * * *$} & $0.3(0.2,0.4) * * *$ \\
\hline \multicolumn{5}{|c|}{ Heard FP messages through media at least once } \\
\hline \multicolumn{5}{|l|}{$\mathrm{No}^{\text {(ref) }}$} \\
\hline Yes & & \multicolumn{2}{|l|}{$1.2(1.0,1.5)^{*}$} & $1.2(1.0,1.4)$ \\
\hline
\end{tabular}

$0.8(0.4,1.6)$

$1.3(1.1,1.5)^{* *}$
Table 3 Multilevel regression results assessing effects of individual and community level characteristics on contraceptive use among women in Ethiopia, 2016 Ethiopian Demographic and Health Survey (Continued)

\begin{tabular}{|c|c|}
\hline $\begin{array}{l}\text { Both wants the } \\
\text { same } e^{(\text {reff }}\end{array}$ & \\
\hline $\begin{array}{l}\text { Husband wants } \\
\text { more }\end{array}$ & $0.8(0.7,0.9) * *$ \\
\hline $\begin{array}{l}\text { Husband wants } \\
\text { fewer }\end{array}$ & $1.0(0.7,1.2)$ \\
\hline Don't know & $0.8(0.7,0.9) * *$ \\
\hline Region & \\
\hline Tigray & \\
\hline Afar & \\
\hline Amhara & \\
\hline Oromia & \\
\hline Somali & \\
\hline Benishangul & \\
\hline $\begin{array}{l}\text { South Nations } \\
\text { Nationalities and } \\
\text { Peoples' Region }\end{array}$ & \\
\hline
\end{tabular}

Visited Health Facility in the last 12 months

$$
\begin{aligned}
& \mathrm{No}^{\text {(reff) }} \\
& \text { Yes }
\end{aligned}
$$$$
1.4(1.3,1.6)^{* * *}
$$$$
1.3(1.1,1.5) * * *
$$

Husbands desire for children

$\begin{array}{lll}\text { Gambela } & 0.8(0.5,1.3) & 0.8(0.5,1.3) \\ \text { Harari } & 1.0(0.6,1.6) & 0.9(0.6,1.4) \\ \text { Dire dawa } & 0.8(0.5,1.3) & 0.8(0.5,1.3)\end{array}$

Addis Ababa (ref)

Place of residence

$$
\text { Urban }^{\text {(ref) }}
$$

$$
\begin{array}{ll}
1.3(0.8,2.0) & 1.3(0.9,2.0) \\
0.3(0.2,0.6) * * * & 0.4(0.2,0.6) * * * \\
2.6(1.7,4.0) * * * & 2.7(1.8,4.1) * * * \\
1.5(0.9,2.3) & 1.5(1.0,2.3) \\
0.1(0.04,0.2) * * * & .1(0.05,0.2) * * * \\
1.3(0.8,2.1) & 1.3(0.8,2.0) \\
2.0(1.3,3.1) * * & 2.1(1.4,3.3) * * *
\end{array}
$$

$2.3(1.8,2.9) * * * \quad 1.7(1.4,2.1) * * *$
Rural

Community-level women employment

$$
\text { low (ref) }
$$$$
\text { High }
$$

$1.3(1.0,1.5) * \quad 1.1(0.9,1.3)$

Wealth index

$$
\text { low }{ }^{\text {(reef) }}
$$$$
\text { High }
$$

Media exposure

$$
\text { low }^{\text {(ref) }}
$$$$
\text { High }
$$$$
1.4(1.1,1.8) * * \quad 1.2(0.9,1.5)
$$

Proportion of Muslims in the cluster low (ref)
$0.5(0.4,0.7) * * * \quad 0.7(0.5,0.9) *$ 
Table 3 Multilevel regression results assessing effects of individual and community level characteristics on contraceptive use among women in Ethiopia, 2016 Ethiopian Demographic and Health Survey (Continued)

\begin{tabular}{lllll}
\hline $\begin{array}{l}\text { Variables/ } \\
\text { characteristics }\end{array}$ & $\begin{array}{l}\text { Null } \\
\text { model }\end{array}$ & Model I & Model II & Model III \\
& $\begin{array}{l}\text { Individual } \\
\text { characteristics }\end{array}$ & $\begin{array}{l}\text { Community } \\
\text { level } \\
\text { characteristics }\end{array}$ & $\begin{array}{l}\text { Individual and } \\
\text { community-level } \\
\text { characteristics }\end{array}$ \\
& OR $(95 \% \mathrm{Cl})$ & OR $(95 \% \mathrm{Cl})$ & OR $(95 \% \mathrm{Cl})$ \\
\hline High & & $0.6(0.5,0.8)^{* * *}$ & $0.6(0.5,0.8)^{* * *}$
\end{tabular}

Health facility visit

Low ${ }^{\text {(ref) }}$

High $\quad 1.3(1.0,1.6) * \quad 1.1(0.9,1.4)$

${ }^{*} P<0.05,{ }^{* *} P<0.001,{ }^{* * *} P<0.0001$

occupation. Different occupations had different odds for women's utilization, professional/technical/managerial and Clerical/sales/services/skilled labor positions of the husband gave highest of odds 1.9, while farming/unskilled followed with odds of 1.6. working women during the time of the survey had higher odds with $1.3(95 \%$ CI 1.1, 1.5), and experience of terminated pregnancy had increased the use of contraceptives in currently in-union women. Women's individual level determinant factors were summarized in Table 3.

\begin{tabular}{lllll}
\hline Random effects & Model 0 & Model I & Model II & Model III \\
\hline ICC (\%) & $40.0 \%$ & $23.0 \%$ & $16.0 \%$ & $14.0 \%$ \\
PCV & NA & $82.5 \%$ & $88 \%$ & $90 \%$ \\
Model fitness & & & & \\
$\quad$ Log likelihood & 3927.16 & -3636.12 & -3634.10 & -3454.60 \\
AIC & 3858.32 & 7334.23 & 7304.17 & 7003.21 \\
BIC & 387.99 & 7545.98 & 7427.16 & 7324.25 \\
\hline
\end{tabular}

\section{Community level determinants}

To examine if the characteristics of the cluster affect women's contraceptive use, regardless of women's individual characteristics, we analyze community-level attributes. In Model II only community-level variables were added. Cluster characteristics like region, place of residence, religion, and community-level poverty were the factors associated with contraceptive use. The ICC in this model implied that difference between communities account for about $16 \%$ of the variation in women's contraceptive use. The PCV also showed that $88 \%$ of the variation in contraceptive use between communities was explained by community level characteristics. As a cluster factor region was a strong predictor of contraceptive use. Considering Addis Ababa, the capital of the country as a reference, dwelling in Amhara region had the highest odds $\mathrm{OR}=2.7$ (95\% CI 1.8-4.1) of contraceptive use. On the contrary Somali region had the lowest odds for contraceptive use OR $=0.1(95 \%$ CI $0.05,0.2)$ compared with the people of the capital.

Compared with urban women, rural women had lower odds for contraceptive use OR $=0.7(95 \%$ CI $0.5,0.9)$, and community-level poverty decreased odds. Wealthy clusters had higher odds than poor clusters, regardless of household wealth index $\mathrm{OR}=1.7(95 \% \mathrm{CI} 1.4,2.1)$. Religious affiliations had an effect on contraceptive utilization, being in a Muslim dominant cluster had lower odds of utilizations $\mathrm{OR}=0.6(95 \% \mathrm{CI} 0.5,0.9)$ after controlling other individual and community level factors. Controlling other individual and community level factors, hearing information about family planning on radio and other information sources in the last few months didn't contribute for utilization $\mathrm{P}$ value $>0.05$ in all cases.

\section{Discussion}

Family planning is one of the four pillars of safe motherhood initiative to reduce maternal death in developing countries. Contraceptives prevent unwanted and unplanned pregnancies, as well as complications, arising from these conditions. Increasing contraceptive use in developing countries has cut maternal death by $40 \%$ in past 20 years, a further $30 \%$ maternal deaths could be averted by fulfilling the unmet needs of family planning [21, 22]. Besides, there are non-contraceptive benefits of using contraception. Contraception can improve perinatal outcomes and child survival mainly by lengthening interpregnancy gaps as shortening the interpregnancy gap have a high risk of prematurity, low birth weight and infant death [23, 24].

In the current EDHS, about $34.9 \%$ of married women used modern contraceptive methods. This figure was much higher than previous percentages of EDHS data. In 2000's and 2005's DHS data contraceptive use was 8 and $14 \%$ respectively [25], further increment in contraceptive use was seen in 2011's DHS survey around 27.3\% [26]. Despite the unmet need for modern contraceptives, Ethiopia showed noteworthy improvement in the percentage of users from previous surveys. This percentage in this study is consistent with EDHS 2016 report of 35\% [20]. The prevalence of contraceptive use in Ghana (2015) was $18.3 \%$ in adolescent females [27], in South Africa (2017) was 41.8\% [28], and $32.1 \%$ in Uganda in 2011 [29]. There were changes annually in modern contraceptive prevalence rates in all women across sub-Saharan Africa with 1.92 percentage points (95\% CI 1.14 to 2.70 ) generally [30].

Household wealth index positively affects contraceptive use in the current study, as found previously [31-33]. In Ethiopia modern contraceptives are available free of charge, the contribution of household wealth for contraceptive use will not be explained by the ability to pay for the service. Rather it reflects the general socioeconomic position of the 
household [34], which fundamentally affects health [35]. Economic status generally is known to increase not only contraceptive use but also other maternal health services in developing countries [36]. The two-way association of maternal health service utilization and contraceptive use have been explained previously [37]. The number of living children determines the odds of using contraception in this study, similar associations were found in the DHS of other countries [38-40]. Having living children between 1 and 4 had higher odds, and the odds increased in women having 5-8 children. In nulliparous women the desired number of children is unmet and the intension to bear a child is high and less likely to use contraceptives. As the number of children increased, women tend to use contraceptive as their desired number of children will be met. While great grand multiparous women might have had no idea about the use of modern contraceptives at all, or sex preference might be there in some women [41].

Women age had also effects on contraceptive use, where younger women had higher odds than older women in child bearing age. Although the denominators are different, similar scenarios have occurred in previous studies [42, 43]. There were improvements in female schooling in Ethiopia in the last few decades, younger females in this DHS might have better educational attainment. Women education at individual level was determinant in this study as well as in the previous studies $[44,45]$. Schooling has positive relationship with contraceptive use and negative relationship with fertility [46], in Ethiopia there are evidences as well. Schooling might have decreased early age fertility and increased contraceptive utilization [47].

Husbands have a determinant role in contraceptive use of their wife, and approval by the husband gives the women higher chance of contraceptive use [48]. If husband's occupation is professional/technical/manager, women have the higher odds of using contraceptive in this study. These husband's occupation may reflect husbands educational status and contributed for contraceptive use by women as indicated [49]. There is a higher possibility that these women can reside in urban regions.

At the community level, there was lower odds of contraceptive use in Muslim dominant clusters. Similarly, women in Muslim communities of Asian countries usually had more children, desire for additional children and if they desire no more children, less likely to use contraceptive methods than the non-Muslims [50]. Urban women uses contraceptive more than the rural, this finding is in agreement with other studies conducted in Ethiopia and different parts of the world [51-53]. Women in the urban areas might have better decision-making confidence, autonomy, availability of contraceptive methods and even better living standards than the rural women. Rural women are prone to gender inequality and female reproductive decisions are dominated by males [54]. Longer distance to the health facility in rural areas was among the barriers [54], more employment opportunities are present in urban areas.

Community level women employment and community level poverty were also significant cluster characteristics affecting contraceptive use. These factors were significant in different studies [55-57]. Economically poorer areas have deficient health facility, even the distance to the health facility will be far. Poorer communities will not invest on women education and women empowerment will be less. Women in higher employed cluster tend to have assertiveness and decision-making power. Community cultural barriers might be minimal in these communities as well.

This study has some strengths. The study used the most recent and representative nationwide surveys. The study also, applied a multilevel analysis to accommodate the hierarchical nature of the Ethiopian Demographic Health Surveys data. Having the above strengths, the study has also some limitations: Since the data used in this study was cross-sectional data, which limits the conclusions about the causality of the factors on the dependent variable. Moreover, recall bias and not using sampling weight for the analysis were the limitations of the study.

\section{Conclusion}

In nutshell, this study indicated both individual and community level factors can influence the use of contraception by women. Wealth index, women's age, number of living children, husband's occupation, ever experience of a terminated pregnancy, current working status of the women, number of births in the last 3 years, and hearing of FP messages through different media were significantly associated individual-level factors. Cluster characteristics like region, place of residence, religion, and community-level poverty were the factors associated with contraceptive use. Individual and community characteristics were significant predictors of use of modern contraceptives in Ethiopia and thus, these factors should be considered in programming for family planning in the country. Both individual and community-level characteristics should be priority areas in future measures to be taken in policies regarding contraceptive use in Ethiopia.

\section{Abbreviations \\ Cl: Confidence interval; EDHS: Ethiopian Demographic and Health Survey; FP: Family planning; HDI: Human development index; ICC: Intra class correlation; OR: Odds ratio; PCV: Proportional change in variance}

\section{Acknowledgments}

The authors would like to acknowledge the DHS program office for giving permission to access the dataset. 


\section{Authors' contributions}

Both authors equally contributed for this work. All authors read and approved the final manuscript.

\section{Funding}

The authors receive no funding for this study.

\section{Availability of data and materials}

The dataset supporting the conclusion of this article is available in the demographic health and survey repository in http://dhsprogram.com/data/.

\section{Ethics approval and consent to participate}

The study doesn't involve the collection of information from subjects. Consent to participate is not applicable. We sent a one-page proposal abstract of the study to the DHS program office. They gave permission to access the data. The consent is available at https://www.dhsprogram.com/ What-We-Do/Protecting-the-Privacy-of-DHS-Survey-Respondents.cfm.

\section{Consent for publication}

Not applicable

\section{Competing interests}

The authors declare that they have no competing interests.

\section{Author details}

'Biostatistics Unit, Department of Epidemiology, Institute of Health, Jimma University, Jimma, Ethiopia. ${ }^{2}$ Department of Biomedical Sciences, Institute of Health, Jimma University, Jimma, Ethiopia.

\section{Received: 20 July 2019 Accepted: 16 September 2019}

Published online: 30 October 2019

\section{References}

1. Tripathi AD, Mishra R, Maurya KK, Singh RB, Wilson DW. Chapter 1 Estimates for World Population and Global Food Availability for Global Health. In: Singh RB, Watson RR, Takahashi T, editors. Role Funct Food Secur Glob Health. Academic Press; 2019 [cited 2019 May 10]. p. 3-24. Available from: http://www.sciencedirect.com/science/article/pii/B97801281314 80000013

2. World population projected to reach 9.7 billion by $2050 \mid$ UN DESA | United Nations Department of Economic and Social Affairs. [cited 2019 May 10]. Available from: 2015-report.html

3. Ethiopia - Demographic and Health Survey 2016. [cited 2019 May 10] Available from: http://microdata.worldbank.org/index.php/catalog/2886

4. Shah S. Determinants of Human Development Index: A Cross-Country Empirical Analysis. 2016 [cited 2019 May 11]. Available from: https://mpra. ub.uni-muenchen.de/73759/

5. Winikoff $B$, Sullivan M. Assessing the role of family planning in reducing maternal mortality. Stud Fam Plann. 1987;18:128-143. [cited 2019 May 11] Available from: http://europepmc.org/abstract/med/3617120

6. Rahman M, DaVanzo J, Razzaque A. Do better family planning services reduce abortion in Bangladesh?. Lancet. 2001;358:1051-1056. [cited 2019 May 11] Available from: http://www.sciencedirect.com/science/article/pii/ S0140673601061827

7. Lakew Y, Reda AA, Tamene H, Benedict S, Deribe K. Geographical variation and factors influencing modern contraceptive use among married women in Ethiopia: evidence from a national population based survey. Reprod Health. 2013;10:52. [cited 2019 may 11] Available from: https://doi.org/10. 1186/1742-4755-10-52

8. Liu L, Oza S, Hogan D, Perin J, Rudan I, Lawn JE, et al. Global, regional, and national causes of child mortality in 2000-13, with projections to inform post-2015 priorities: an updated systematic analysis. Lancet. 2015;385:430440. [cited 2019 May 11] Available from: http://www.sciencedirect.com/ science/article/pii/S0140673614616986

9. Requejo $\mathrm{JH}$, Bhutta ZA. The post-2015 agenda: staying the course in maternal and child survival. Arch Dis Child. 2015;100:S76-S81. [cited 2019 May 11] Available from: https://adc.bmj.com/content/100/Suppl_1/S76

10. Chola L, McGee S, Tugendhaft A, Buchmann E, Hofman K. Scaling Up Family Planning to Reduce Maternal and Child Mortality: The Potential Costs and Benefits of Modern Contraceptive Use in South Africa. Plos One. 2015;10: e0130077. [cited 2019 May 11] Available from: https://journals.plos.org/ plosone/article?id=10.1371/journal.pone.0130077

11. Melka AS, Tekelab T, Wirtu D. Determinants of long acting and permanent contraceptive methods utilization among married women of reproductive age groups in western Ethiopia: a cross-sectional study. Pan Afr Med J. 2015;21 [cited 2019 May 11]. Available from: https://www.ncbi.nlm.nih.gov/ pmc/articles/PMC4607985/

12. Getahun DS, Wolde HF, Muchie KF, Yeshita HY. Utilization and determinants of long term and permanent contraceptive methods among married reproductive age women at Janamora district, northwest Ethiopia. BMC Res Notes. 2018;11 [cited 2019 May 11]. Available from: https://www.ncbi.nlm. nih.gov/pmc/articles/PMC6257970/

13. Gebeyehu A, Asnake M, Dibaba Y, Setegn T, Yirga M, Teklu AM, et al. Barriers to utilization of long acting reversible and permanent contraceptive methods in Ethiopia: systematic review. Ethiop J Reprod Health. 2018;10 [cited 2019 May 11]. Available from: http://ejrh.org/index.php/ejrh/article/view/220

14. Mohammed A, Woldeyohannes D, Feleke A, Megabiaw B. Determinants of modern contraceptive utilization among married women of reproductive age group in North Shoa Zone, Amhara Region, Ethiopia. Reprod Health. 2014;11:13 [cited 2019 May 11]. Available from: https://www.ncbi.nlm.nih. gov/pmc/articles/PMC3918182/

15. Ayele W, Tesfaye H, Gebreyes R, Gebreselassie T. Trends and determinants of unmet need for family planning and programme options, Ethiopia: Further analysis of the 2000, 2005, and 2011 Demographic and Health Surveys. 2013 [cited 2019 May 11]; Available from: https://www.dhsprogram. com/publications/publication-FA81-Further-Analysis.cfm

16. Okigbo C, Speizer I, Domino M, Curtis S. A multilevel Logit estimation of Factors associated with modern contraception in urban Nigeria. World Med Health Policy. 2017:9:65-88.

17. Ejembi CL, Dahiru T, Aliyu AA. Contextual factors influencing modern contraceptive use in Nigeria. 2015 [cited 2019 Aug 23]; Available from: https:// dhsprogram.com/publications/publication-wp120-working-papers.cfm

18. Dias JG, de Oliveira IT. Multilevel Effects of Wealth on Women's Contraceptive Use in Mozambique. PLoS One. 2015:10:e0121758.

19. Colleran H, Mace R. Social network- and community-level influences on contraceptive use: evidence from rural Poland. Proc R Soc B Biol Sci. 2015; 282:20150398

20. The DHS Program - Ethiopia: Standard DHS, 2016. [cited 2019 Jun 3]. Available from: https://dhsprogram.com/what-we-do/survey/surveydisplay-478.cfm

21. Ahmed S, Li Q, Liu L, Tsui AO. Maternal deaths averted by contraceptive use: an analysis of 172 countries. Lancet. 2012;380:111-125 [cited 2019 May 30]. Available from: http://www.sciencedirect.com/science/article/pii/S01406 73612604784

22. Cleland J, Conde-Agudelo A, Peterson H, Ross J, Tsui A. Contraception and health. Lancet. 2012;380:149-156 [cited 2019 May 30]. Available from: http:// www.sciencedirect.com/science/article/pii/S0140673612606096

23. Conde-Agudelo A, Rosas-Bermúdez A, Kafury-Goeta AC. Birth spacing and risk of adverse perinatal outcomes: a meta-analysis. JAMA. 2006;295:1809-23.

24. Hanley GE, Hutcheon JA, Kinniburgh BA, Lee L. Interpregnancy interval and adverse pregnancy outcomes: an analysis of successive pregnancies. Obstet Gynecol. 2017;129:408-15.

25. Unmet need and evaluation of programme options to meet unmet need for contraception in Ethiopia, 200 ... | POPLINE.org. [cited 2019 May 20]. Available from: https://www.popline.org/node/204205

26. Lakew Y, Reda AA, Tamene H, Benedict S, Deribe K. Geographical variation and factors influencing modern contraceptive use among married women in Ethiopia: evidence from a national population based survey. Reprod Health. 2013;10:52 [cited 2019 may 20]. Available from: https://doi.org/10. 1186/1742-4755-10-52.

27. Nyarko SH. Prevalence and correlates of contraceptive use among female adolescents in Ghana. BMC Womens Health. 2015;15:60 [cited 2019 Aug 23] Available from: https://doi.org/10.1186/s12905-015-0221-2.

28. Chersich MF, Wabiri N, Risher K, Shisana O, Celentano D, Rehle T, et al. Contraception coverage and methods used among women in South Africa: A national household survey. S Afr Med J. 2017:107:307-314 [cited 2019 Aug 23]. Available from: https://www.ajol.info/index.php/samj/article/view/154520

29. Andi JR, Wamala R, Ocaya B, Kabagenyi A. Modern contraceptive use among women in Uganda: An analysis of trend and patterns (1995-2011). Etude Popul Afr Afr Popul Stud. 2014:28:1009-1021 [cited 2019 Aug 23]. Available from: https://www.ncbi.n/m.nih.gov/pmc/articles/PMC4269974/ 
30. Ahmed S, Choi Y, Rimon JG, Alzouma S, Gichangi P, Guiella G, et al. Trends in contraceptive prevalence rates in sub-Saharan Africa since the 2012 London Summit on Family Planning: results from repeated cross-sectional surveys. Lancet Glob Health. 2019;7:e904-e911 [cited 2019 Aug 23]. Available from: http://www.sciencedirect.com/science/article/pii/S2214109X19302001

31. González C, Houweling TA, Marmot MG, Brunner EJ. Comparison of physical, public and human assets as determinants of socioeconomic inequalities in contraceptive use in Colombia - moving beyond the household wealth index. Int J Equity Health. 2010;9:10 [cited 2019 may 21]. Available from: https://doi.org/10.1186/1475-9276-9-10.

32. Gakidou E, Vayena E. Use of Modern Contraception by the Poor Is Falling Behind. PLOS Med. 2007:4:e31 [cited 2019 May 21]. Available from: https:// journals.plos.org/plosmedicine/article?id=10.1371/journal.pmed.0040031

33. Adebowale SA, Adedini SA, Ibisomi LD, Palamuleni ME. Differential effect of wealth quintile on modern contraceptive use and fertility: evidence from Malawian women. BMC Womens Health. 2014;14:40 [cited 2019 may 21]. Available from: https://doi.org/10.1186/1472-6874-14-40.

34. Vyas S, Kumaranayake L. Constructing socio-economic status indices: how to use principal components analysis. Health Policy Plan. 2006;21:459-68.

35. Report I of M (US) C on G for D a NHD, Swift EK. Measuring the effects of socioeconomic status on health care. National Academies Press (US); 2002 [cited 2019 May 21]. Available from: https://www.ncbi.nlm.nih.gov/books/ NBK221050/

36. Ahmed S, Creanga AA, Gillespie DG, Tsui AO. Economic Status, Education and Empowerment: Implications for Maternal Health Service Utilization in Developing Countries. PLoS One. 2010;5 [cited 2019 May 30]. Available from: https://www.ncbi.n/m.nih.gov/pmc/articles/PMC2890410/

37. Ahmed S, Mosley WH. Simultaneity in the use of maternal-child health care and contraceptives: evidence from developing countries. Demography. 2002;39:75-93 [cited 2019 may 30]. Available from: https://doi.org/10.1353/ dem.2002.0001.

38. Paudel $\mathrm{YR}$, Acharya K. Fertility Limiting Intention and Contraceptive Use among Currently Married Men in Nepal: Evidence from Nepal Demographic and Health Survey 2016. BioMed Res Int. 2018;2018 [cited 2019 May 29]. Available from: https://www.ncbi.nlm.nih.gov/pmc/articles/PMC6323452/

39. Osmani AK, Reyer JA, Osmani AR, Hamajima N. Factors influencing contraceptive use among women in Afghanistan: secondary analysis of Afghanistan Health Survey 2012. Nagoya J Med Sci. 2015;77:551-561 [cited 2019 May 29]. Available from: https://www.ncbi.nlm.nih.gov/pmc/articles/ PMC4664587/

40. Palamuleni ME. Socio-Economic and Demographic Factors Affecting Contraceptive use in Malawi. Afr J Reprod Health. 2013;17:91-104 [cited 2019 May 29]. Available from: https://www.ajol.info/index.php/ajrh/article/ view/93751

41. Narzary PK, Sharma SM. Daughter Preference and Contraceptive-use in Matrilineal Tribal Societies in Meghalaya, India. J Health Popul Nutr. 2013;31: 278 [cited 2019 May 29]. Available from: https://www.ncbi.nlm.nih.gov/pmc/ articles/PMC3702350/

42. Muyindike W, Fatch R, Steinfield R, Matthews LT, Musinguzi N, Emenyonu $\mathrm{Nl}$, et al. Contraceptive Use and Associated Factors among Women Enrolling into HIV Care in Southwestern Uganda. Infect Dis Obstet Gynecol. 2012;2012 [cited 2019 May 30]. Available from: https://www.ncbi.nlm.nih. gov/pmc/articles/PMC3469089/

43. Frost JJ, Singh S, Finer LB. Factors Associated with Contraceptive Use and Nonuse, United States, 2004 Perspect Sex Reprod Health. 2007;39:90-99 [cited 2019 May 30]. Available from: https://onlinelibrary.wiley.com/doi/ abs/10.1363/3909007

44. Asiimwe JB, Ndugga P, Mushomi J, Manyenye Ntozi JP. Factors associated with modern contraceptive use among young and older women in Uganda; a comparative analysis. BMC Public Health. 2014;14:926 [cited 2019 may 30]. Available from: https://doi.org/10.1186/1471-2458-14-926.

45. Saleem S, Bobak M. Women's autonomy, education and contraception use in Pakistan: a national study. Reprod Health. 2005;2:8 [cited 2019 may 30]. Available from: https://doi.org/10.1186/1742-4755-2-8.

46. Bongaarts $\mathrm{J}$. The causes of educational differences in fertility in sub-Saharan Africa. Poverty Gend Youth. 2010; Available from: https:// knowledgecommons.popcouncil.org/departments_sbsr-pgy/157.

47. Pradhan E, Canning D. The Effect of Schooling on Teenage Fertility: Evidence from the 1994 Education Reform in Ethiopia. Program on the Global Demography of Aging; 2016. Report No.: 12816. Available from: https://ideas.repec.org/p/gdm/wpaper/12816.html
48. Kamal N. The influence of husbands on contraceptive use by Bangladeshi women. Health Policy Plan. 2000;15:43-51.

49. Gubhaju B. The influence of wives' and husbands' education levels on contraceptive method choice in Nepal, 1996-2006. Int Perspect Sex Reprod Health. 2009;35:176-85.

50. Morgan SP, Stash S, Smith HL, Mason KO. Muslim and Non-Muslim Differences in Female Autonomy and Fertility: Evidence from Four Asian Countries. Popul Dev Rev. 2002;28:515-537 [cited 2019 May 30]. Available from: https:// onlinelibrary.wiley.com/doi/abs/10.1111/j.1728-4457.2002.00515.x

51. Towriss C, Timaeus I. Contraceptive use and lengthening birth intervals in rural and urban Eastern Africa. Demogr Res. 2018:38:2027-2052 [cited 2019 Jun 3]. Available from: https://www.demographic-research.org/volumes/vol38/64/

52. Alemayehu T, Haider J, Habte D. Determinants of adolescent fertility in Ethiopia. Ethiop J Health Dev. 2010;24 [cited 2019 Jun 3]. Available from: https://www.ajol.info/index.php/ejhd/article/view/62942

53. Paul B, Ayo AS, Ayiga N. Rural-Urban Contraceptive Use in Uganda: Evidence from UDHS 2011. J Hum Ecol. 2015;52:168-182 [cited 2019 Jun 3]. Available from: https://doi.org/10.1080/09709274.2015.11906941.

54. Dodoo FN-A, Tempenis M. Gender, Power, and Reproduction: Rural-Urban Differences in the Relationship Between Fertility Goals and Contraceptive Use in Kenya*. Rural Sociol. 2002;67:46-70 [cited 2019 Jun 3]. Available from: https://onlinelibrary.wiley.com/doi/abs/10.1111/j.1549-0831.2002.tb00093.x

55. Stephenson R, Baschieri A, Clements S, Hennink M, Madise N. Contextual influences on modern contraceptive use in sub-Saharan Africa. Am J Public Health. 2007:97:1233-40.

56. Bentley R, Kavanagh A, Smith A. Area disadvantage, socioeconomic position and women's contraception use: a multilevel study in the UK. J Fam Plann Reprod Health Care. 2009;35:221-6.

57. Janevic T, Sarah PW, Leyla I, Elizabeth BH. Individual and community level socioeconomic inequalities in contraceptive use in 10 Newly Independent States: a multilevel cross-sectional analysis. Int J Equity Health. 2012;11:69 [cited 2019 Jun 4]. Available from: https://doi.org/10.1186/1475-9276-11-69.

\section{Publisher's Note}

Springer Nature remains neutral with regard to jurisdictional claims in published maps and institutional affiliations.

Ready to submit your research? Choose BMC and benefit from

- fast, convenient online submission

- thorough peer review by experienced researchers in your field

- rapid publication on acceptance

- support for research data, including large and complex data types

- gold Open Access which fosters wider collaboration and increased citations

- maximum visibility for your research: over $100 \mathrm{M}$ website views per year

At BMC, research is always in progress.

Learn more biomedcentral.com/submissions 